X. Cerda

\title{
Indirect effects of alternative food resources in an ant-plant interaction
}

\begin{abstract}
The seeds of many plant species present a food body that is consumed by animal dispersers. In theory, if the animals are polyphagous, the availability of alternative food resource other than the diaspore itself may influence its dispersal and survival. We used the myrmecochore Helleborus foetidus L. (Ranunculaceae), the seeds of which are attached to a lipid-rich elaiosome that is attractive to ants, as a model system to investigate (1) whether alternative foods that are present along with the plant affect ant foraging behavior and diaspore removal and (2) whether food availability in an ant nest affects seed predation and germination. In a field experiment, artificial diaspore depots were offered together with either sugar, insect corpses, seed, or no food (control). Contrary to the prediction that ants would rather concentrate their foraging effort on the highly rewarding alternative foods only, many workers, attracted by the sugar, switched to the hellebore diaspores, which significantly enhanced removal rate. Results obtained in the laboratory further indicated that the larvae of Aphaenogaster iberica (a major seed disperser) predated more on the $\mathrm{H}$. foetidus embryos when no alternative food was available. This, in turn, slightly reduced seed germination. Overall, these results shed light, for the first time, on the potential indirect effects of alternative resources on the fate of diaspores adapted for ant dispersal.
\end{abstract}

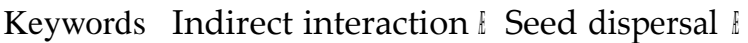
Behavior-mediated effects \& Helleborus foetidus \& Myrmecochory

Communicated by Christian Koerner

R. Boulay $(\&)$ \& J. M. Fedriani $₫$ A. J. Manzaneda $\&$ X. Cerda Departamento de Biologia Evolutiva, Estacion Biologica de Donana, CSIC Avenida Maria Luisa s/n, Pabellon del Peru, E-41013 Sevilla, Spain

E-mail: boulay@ebd.csic.es

Fax: +34-95-4621125

\section{Introduction}

Plant population structure depends on animals' foraging and feeding behaviors (Thomson and Chittka 2001; Danell and Bergstrom 2002) and is therefore influenced by the availability and composition of alternative food resources. Polyphagous species, either antagonists or mutualists, can commonly find various alternative foods concentrated in the microsite where a partner plant is located. For instance, in semiarid habitats, generalist granivors can be attracted by small patches of shrubs and herbs that are separated by gaps of lower biomass production where they can feed on different kinds of seeds. These plants are inhabited by phytophagous invertebrates and can thus also provide food for animals having a mixed diet of insects and seeds. In theory, such associations are likely to provoke short-term indirect interactions between a focused plant and the alternative resources through behavioral modifications of their common feeders (Holt and Kotler 1987; Wootton 1994; Werner and Peacor 2003). On the one hand, the presence of a highly rewarding food near the plant may induce an aggregation of consumers in the patch that will feed on the alternative food as well as on the plant itself even if the latter is less preferred. This would lead to an augmentation of plant consumption when it occurs together with the alternative food. On the other hand, if the quantity of the alternative resource is sufficiently high, the animal can reach satiation before switching to the plant, resulting in a diminution of plant consumption.

These models have been empirically tested in relatively simple situations where desert plants are predated by small rodents. Brown and Mitchell (1989) and Veech (2000) simulated mixed patches of seeds and demonstrated that the survival of less attractive seeds was lower when they were offered together with preferred ones due to the indirect effect of common feeders. However, as suggested by these authors, the outcome of indirect interactions can become more difficult to decipher if the consumer is able to interact with the plant both nega- 

tively and positively. This may be frequent with central place foraging species that accumulate reserves in a nest or a cache before feeding on them. In that case, an individual that stores several species of seeds may further select some of them and reject others, therefore acting either as seed predator or as seed disperser. In addition, the alternative resource may attract various competing animal species that have contrasting effects on the plant, and in excluding each other, make the net indirect effect even more difficult to predict.

Myrmecochory provides a good example of such a complex situation. It consists of a diffused interaction in which plant diaspores bearing a food body (elaiosome) are dispersed by ants (Sernander 1906; Berg 1975; Beattie and Hughes 2002). Foraging workers of omnivorous species transport the diaspores to their nest where the brood consumes the elaiosomes while the unharmed seeds are discarded inside or outside the nest. Although myrmecochory apparently results in reciprocal benefits to both partners, the end result can vary extremely according to the ant involved. Hence, while many ant species disperse myrmecochorous plants, others totally ignore elaiosome bearing seeds or feed on the elaiosomes without dispersing the seed or feed on both the elaiosome and the seed (Rodgerson 1998; Gorb and Gorb 1999). Because allospecific aggressions are common in ants, diaspore dispersal might depend on which ant species are attracted to the plant microsite and how they will interact. Later, seed mortality due to ant larvae predation might also depend on whether they have access to alternative preferred food or not.

In the present study, we uncover the indirect effects of alternative food resources that can occur together with the myrmecochore Helleborus foetidus L. (Ranunculaceae) on the fate on its diaspores. In the mountainous regions of southern Spain, this perennial herb lives either in open gaps and clearings or underneath small trees and shrubs that form patches where various ant species can collect nectars, aphid honeydew, and non-myrmecochorous seeds, or prey on arthropods-mostly phytophagous insects. To reduce the complexity of this situation, we adopt an experimental approach in which diaspores of $\mathrm{H}$. foetidus were offered with or without three types of artificial foods. In a field experiment we questioned whether or not alternative food indirectly changed diaspore removal rate. We reasoned that diaspore removal would decrease if the alternative food mostly attracted species that do not carry out myrmecochorous seeds or if it reduced the dispersers' chances to remove diaspores (e.g., if they preferred to forage on the alternative food or if aggressive interactions with other ants reduced patch access). Alternatively, diaspore removal would be favored if enriched patches were more frequently visited by dispersing species and if many of them switched to the hellebore diaspores. In a laboratory experiment we investigated whether alternative resources indirectly reduced seed predation by ant larvae and favored germination. To our knowledge, this is the first insight into the complex indirect effects of alternative food on diaspore fate arising through successive modifications of animal foraging and feeding decisions.

\section{Material and methods}

\section{Model system and field sites}

The stinking hellebore, $\mathrm{H}$. foetidus, is broadly distributed in Western Europe (Werner and Ebel 1994). Details about the floral biology of this winter-bumblebee pollinated plant in the Iberian Peninsula can be found in Herrera et al. (2001). At the study site (Sierra de Cazorla, SE Spain, $37^{\circ} 56 \mathrm{cN}, 2^{\circ} 52 \mathrm{cW}$ ) adult plants are composed of 1-4 (most commonly 1-2) reproductive stalks. In June, each of 1-3 carpels, composing a fruit, progressively open and release about ten diaspores bearing a lipid-rich elaiosome. Foraging ants remove diaspores on the ground or climb on the plant to collect them directly from dehiscing fruits. During most of the plant cycle, small colonies of aphids (mostly Macrosiphum hellebori) live on the sepals and branches and can provide additional sources of sugar to Camponotus ant species (A. J. Manzaneda, personal observation).

The climate of Sierra de Cazorla is typical Mediterranean characterized by dry-hot summers with most of the precipitation concentrated in the colder winter months (November-April). The field experiment was conducted in three populations separated by about $2 \mathrm{~km}$, and located between $1,280 \mathrm{~m}$ and $1,400 \mathrm{~m}$ elevation. The vegetation does not differ greatly between the three sites and consists of open grasslands with scattered pine (Pinus nigra), oak trees (Quercus rotundifolia), and shrubs (Q. ilex, Juniperus oxycedrus and Rubus ulmifolius).

The effect of alternative food on ant visits and diaspore removal in the field

This experiment aimed at determining if food resources associated with hellebore diaspore depots could quantitatively or qualitatively affect ant visits and consequently, removal rates. Observations were conducted during late June (end of the ripening period) in the three populations described above. Experimental units (EUs) consisted of pairs of $3 \mathrm{~cm}$ diameter Petri dishes. One dish (hellebore dish hereafter) contained 20 freshly collected $\mathrm{H}$. foetidus diaspores while the second dish (food dish hereafter) contained one of the following food types: sesame seeds ( $2 \mathrm{~g}$, seed hereafter), or Tenebrio molitor worms cut in small pieces ( $2 \mathrm{~g}$, insect hereafter), or honey solution $(2 \mathrm{ml}$ of a $20 \% \mathrm{v} / \mathrm{v}$ solution, sugar hereafter) or no food (control). These food types simulate non-myrmecochorous seeds, insect corpses and Homopteran honeydew that ants are likely to find near the plants. The two dishes composing an EU were set on the ground $5 \mathrm{~cm}$ apart from each other, in a manner that ants visiting the food dish could easily discover the 
respective hellebore dish and vice versa. Experimental units were grouped by blocks of four around $\mathrm{H}$. foetidus shoots (at about $1 \mathrm{~m}$ ) including the four food types. Twenty blocks (=80 EUs) were distributed in each population with at least $5 \mathrm{~m}$ between two blocks. A wire mesh allowing free ant passage covered hellebore and food dishes to exclude vertebrates-mostly rodents.

The experiment was set at 0800 and surveyed from 0900 to 2100 (or until the $20 \mathrm{H}$. foetidus diaspores of the EU had been removed). Ant presence in hellebore and food dishes was assessed every $2 \mathrm{~h}$. When ants were present in hellebore dishes, their behavior was observed for $3 \mathrm{~min}$ in order to distinguish between carrying and non-carrying ants. Carrying species were those observed at least once removing a diaspore from the dish. Conversely, species that always ignored or explored the diaspores or fed on the elaiosome in situ were considered non-carrying ants. Remaining diaspores were counted $12 \mathrm{~h}$ and $24 \mathrm{~h}$ after the first census (that is, at 2100 and 0900 of the next day, respectively). Alternative food but not $H$. foetidus diaspores, was applied several times during the experiment as necessary to ensure ad libitum access.

The effect of alternative food on diaspore predation and germination

In this laboratory experiment, the effects of the availability of alternative food on seed predation and seed germination were assessed using captive colonies of three major dispersers: Aphaenogaster iberica $(n=8)$, Camponotus cruentatus $(n=4)$ and Pheidole pallidula $(n=6)$. Source colonies containing between 500 and 1,000 workers and brood were collected during the spring in Sierra de Cazorla, near the study site. All but four colonies of A. iberica had a queen when the experiment was conducted. Colonies of $\mathrm{C}$. cruentatus were also monogynous while those of $\mathrm{P}$. pallidula were either mono- or digynous. Laboratory conditions were 12:12 $\mathrm{h}$ light-dark and temperature ranged between $22^{\circ} \mathrm{C}$ and $26^{\circ} \mathrm{C}$. Size of artificial nests was adapted to species-specific worker and colony sizes: $17-17-5 \mathrm{~cm}$ for A. iberica and C. cruentatus and 5-5-2 cm for P. pallidula. Ants had permanent access to water retained in test tubes $(7-0.5 \mathrm{~cm})$ by means of a cotton plug. Each nest was connected through a Tygon tube to a foraging area $(17-17-5 \mathrm{~cm})$. Between tests, colonies were reared with equal diet of dead insects (mealworms or small crickets) and carbohydrates $(20 \% \mathrm{v} / \mathrm{v}$ honey solution) supplied twice a week.

Mature hellebore fruits were collected in Sierra de Cazorla in June 2003 and conserved at $6^{\circ} \mathrm{C}$ for up to 7 weeks. A total of 66 lots of 20 diaspores were assayed by offering them to the ants during a $72 \mathrm{~h}$ period either with or without alternative food. Alternative food was a mixture of dead mealworms, honey ( $20 \mathrm{v} / \mathrm{v}$ in water), and sesame seeds in quantities similar to those used in the field experiment and was renewed daily to ensure ad libitum access. Each colony was used in the same number of tests with and without alternative food either two, four or six times with a delay of at least $72 \mathrm{~h}$ between two consecutive tests. Successive tests with and without alternative food were done in no fixed order.

At the end of each bioassay, nests and foraging areas were carefully inspected so that diaspores could be removed for examination. They were carefully examined through a magnifying glass and classified as processed or not processed. By 'processed' we mean diaspores from which the elaiosome had been partially or totally removed and/or presenting tegument damage. The 20 diaspores of each lot were then tested for germination. $\mathrm{H}$. foetidus normally requires a 1-3 year dormancy to germinate. However, the process was accelerated by maintaining the seeds at $6^{\circ} \mathrm{C}$ during two periods of 15 days with a 15-day interval at room temperature (Sanchez Yelamo and Ayerbe 1984). They were then placed on Whatman paper moistened with distilled water in Petri dishes $(9-1 \mathrm{~cm})$ and kept in a germinator at $25^{\circ} \mathrm{C}$ under 12:12 LD cycle. The number of germinated seeds was counted after 3 weeks.

\section{Statistical analysis}

Ant visits were estimated using two indexes. First, the number of records of each species represented the total number of censuses in which they were observed in food and hellebore dishes. Second, carrier and non-carrier relative visit frequencies were calculated as the number of censuses in which at least one worker of the respective category was observed in a dish, divided by the total number of censuses for that dish. The effect of alternative food on carrier and non-carrier relative visit frequencies in the EUs was tested, fitting data to Generalized Linear Models (GLM) with the binomial error distribution and Logit link function. The GLIMMIX macro for SAS system (Littell et al. 1996) was employed because it allows inclusion of random factors into non-linear models. "Food" and "Carrying status" were treated as between-subject fixed factors with four (seed, sugar, insect and control) and two (carrier and non-carrier) levels, respectively. "Dish" was introduced as a within-subject fixed factor with two levels to differentiate the effects on food and hellebore dishes inside EUs. "Population" and "Block" (nested in Population) were both treated as random factors. The effect of "Food" (fixed factor) on the number of removed seeds at 12 and $24 \mathrm{~h}$ was tested using the Poisson error distribution and Log link function. Multiple comparisons of estimated least square means were performed using t-test with no adjustment (SAS institute 2000).

In the second experiment, the lots of diaspores were the EUs. Numbers of processed and germinated diaspores per lot were fitted with GLM using the GENMOD procedure from SAS (Poisson error distribution, log link function) including "Ant species", "Food" and "Colony" nested in "Ant species" as fixed factors. The Wald 
chi-square statistic was used to test differences between least-square means (SAS institute 2000). All presented estimates were back transformed.

\section{Results}

The effect of alternative food on diaspore removal in the field

A few minutes were enough to observe ants removing all types of food and hellebore diaspores. In the first $12 \mathrm{~h}$ of the experiment, a total of 1,386 censuses were carried out during which 17 ant taxa were found either in food or in hellebore dishes (Table 1). The number of records and behavior of the different ant species varied greatly. The carpenter ant $C$. cruentatus and the tiny $P$. pallidula were the most frequently observed species, each accounting for more than $20 \%$ of the visits. These and six other species were carrying species (Table 1, species name followed by ${ }^{a}$ ) while the nine remaining taxa mostly ignored hellebore diaspores or, at most, chewed the elaiosome. Most of these ants are nectarivorous or scavengers, but three carrying species (Messor capitatus P. pallidula and A. iberica) also forage on non-myrmecochorous seeds. Minute species of the genus Leptothorax and Tetramorium were difficult to identify in the field but further laboratory specimen examination revealed that they included L. unifasciatus, L. racovitzae, $L$. recedens and $L$. rabaudi, and $T$. caespitum and $T$. hispanicum, respectively.

The relative visit frequency to food and hellebore dishes depended significantly on the type of alternative food and differed between carriers and non-carriers
(Table 2). Carrying species were more frequently observed in sugar food dishes than in insect (Fig. 1a; $t$ test: $\mathrm{t}=2.11, \mathrm{P}=0.0348)$, seed $(\mathrm{t}=7.00, \mathrm{P}<0.0001)$ and control food dishes $(\mathrm{t}=8.16, \mathrm{P}<0.0001)$. Non-carrying species were less frequent than carrying ones; they preferred sugar to seed and control food dishes ( $\mathrm{t}$-test: $\mathrm{t}=2.56, \quad \mathrm{P}=0.0107 ; \mathrm{t}=3.96, \mathrm{P}<0.0001$, respectively) but not insect food dishes $(t=1.83, P=0.0676)$. Not surprisingly, control (empty) dishes were almost never visited irrespective of the carrying status. Both carriers and non-carriers were less frequent in hellebore than in food dishes. Carrying species were significantly more abundant in hellebore dishes associated with sugar, dead insects and seeds than in control hellebore dishes (Fig. 1b; t-test: $\mathrm{t}=2.77, \mathrm{P}=0.0058 ; \mathrm{t}=1.99, \mathrm{P}=0.0471$; $\mathrm{t}=2.41, \mathrm{P}=0.0160$, respectively). The presence of noncarriers in hellebore dishes was less frequent irrespective of the associated food dish.

Ant visits resulted in intensive hellebore diaspore removal. After the first $12 \mathrm{~h}$ of the experiment, more than $71 \%$ of the diaspores had disappeared and $35 \%$ of the hellebore dishes were totally empty. At that point, the three types of food associated dishes contained significantly less diaspores than the controls ( $\mathrm{t}$-test: $\mathrm{t}=2.03$, $\mathrm{P}=0.0440 ; \mathrm{t}=3.39, \mathrm{P}=0.0009$ and $\mathrm{t}=2.06, \mathrm{P}=0.0407$ for control versus seed, sugar and insect, respectively). Ants continued removing diaspores during the night and early morning, and only $13.6 \%$ of the diaspores remained at $24 \mathrm{~h}$. When the experiment ended (Table 3, Fig. 2) ants had removed significantly more hellebore diaspores in depots associated with sugar than in those associated with seed, insect or control food dishes (t-test: $\mathrm{t}=2.06, \mathrm{P}=0.0406 ; \mathrm{t}=2.21, \mathrm{P}=0.0281$ and $\mathrm{t}=3.38$, $\mathrm{P}=0.0009$ respectively).

Table 1 Number of records of ant taxa in food dishes only, hellebore dishes only and in both food and hellebore dishes

\begin{tabular}{|c|c|c|c|c|}
\hline Ant taxa & $\begin{array}{l}\text { Presence in } \\
\text { food dish only }\end{array}$ & $\begin{array}{l}\text { Presence both in } \\
\text { food and } \\
\text { hellebore dishes }\end{array}$ & $\begin{array}{l}\text { Presence } \\
\text { in hellebore } \\
\text { dish only }\end{array}$ & $\%$ of diaspore carrying \\
\hline Aphaenogaster iberica $(\mathrm{s}, \mathrm{g})^{\mathrm{a}}$ & 34 & 10 & 14 & 100 \\
\hline Camponotus cruentatus $(n, s)^{a}$ & 183 & 24 & 54 & 54 \\
\hline Camponotus piceus (n) & 6 & 2 & 1 & 0 \\
\hline Camponotus pilicornis (n) & 10 & 0 & 3 & 0 \\
\hline Camponotus vagus $(n, s)^{a}$ & 5 & 0 & 2 & 50 \\
\hline Cataglyphis velox (s) ${ }^{a}$ & 44 & 6 & 12 & 26 \\
\hline Crematogaster scutellaris $(\mathrm{n}, \mathrm{s})$ & 11 & 6 & 2 & 0 \\
\hline Crematogaster sordidula (n) & 2 & 0 & 2 & 0 \\
\hline Formica gerardi (n) & 7 & 4 & 3 & 0 \\
\hline Lasius niger $(n, s)^{a}$ & 22 & 26 & 18 & 64 \\
\hline Leptothorax spp. (o) & 14 & 6 & 41 & 0 \\
\hline Pheidole pallidula $(\mathrm{s}, \mathrm{g}, \mathrm{n})^{\mathrm{a}}$ & 103 & 50 & 51 & 76 \\
\hline Plagiolepis pygmaea $(\mathrm{n}, \mathrm{o})$ & 27 & 0 & 5 & 0 \\
\hline Messor capitatus (g) ${ }^{\text {a }}$ & 5 & 2 & 1 & 50 \\
\hline Myrmica ruginodis (s, $\mathrm{n}$ ) & 7 & 2 & 4 & 0 \\
\hline Tapinoma erraticum (n, $s)^{a}$ & 11 & 0 & 4 & 25 \\
\hline Tetramorium spp. (o) & 21 & 4 & 3 & 0 \\
\hline
\end{tabular}

The last column indicates percentage of diaspore carrying behaviors. A total of 1,386 census were completed during the first $13 \mathrm{~h}$ of experiment. Carrying species are followed by ${ }^{\mathrm{a}}$. Letters beside taxa names indicate their diet $\mathrm{n}$ nectarivorous and aphid tenders, s scavenger, g granivorous and o omnivorous 
Table 2 Result of the GLM fitting the relative visit frequency of ants in the EUs as a function of food type (sugar, seed, insect and control), carrying status (diaspore carrying vs non diaspore carrying species) and dish type (hellebore versus food dish)

\begin{tabular}{llcc}
\hline Fixed effects & Df (Numerator) & Df (Denominator) & F \\
\hline Food type (between subject) & 3 & 885 & 23.95 \\
Carrying status (between subject) & 1 & 885 & $<8.61$ \\
Dish type (within subject) & 1 & 885 & $<0.0001$ \\
Food type-Carrying status & 3 & 885 & 0.0001 \\
Food type-Dish type & 3 & 885 & 1.07 \\
Carrying status-Dish type & 1 & 885 & 7.75 \\
Food type-Carrying status-Dish type & 3 & 885 & 0.3588 \\
Random effects & & & $<0.0001$ \\
Population & & & 0.3807 \\
Block & & 0.5899 \\
\hline
\end{tabular}

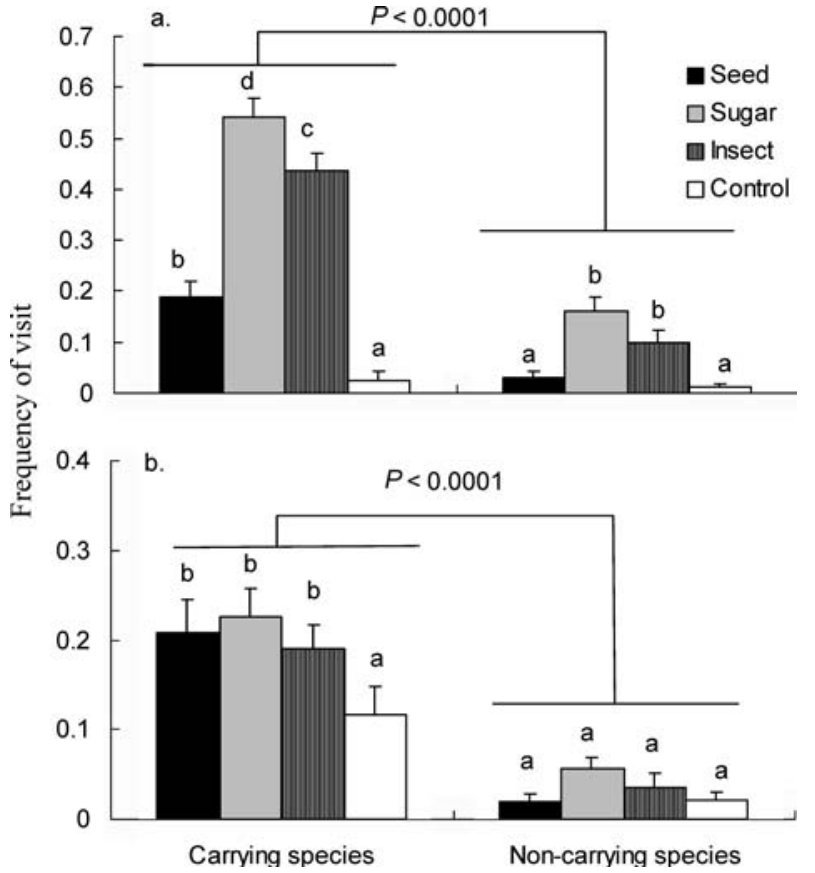

Fig. 1 Frequency of visit (mean \pm sem) of dispersing and nondispersing ant species in the food (a) and hellebore (b) dishes as a function of the associated food. A total of 1,386 censuses were made during the first $12 \mathrm{~h}$ of experiment. $\mathrm{n}=240$ experimental units. Among dispersal status, different letters denote significant differences. Multiple comparisons of least-square means were performed with t-test
The effect of alternative food on diaspore predation

In laboratory colonies, ants rapidly carried off the diaspores to their nests. After $72 \mathrm{~h}$ most diaspores (including the processed ones) were recovered outside the nests indicating that after this period of time they had lost most of their attractiveness, and more transport and processing were unlikely. The number of processed diaspores differed significantly between the three species but not between colonies within species (Table 4). Workers of C. cruentatus and P. pallidula processed significantly less diaspores than A. iberica (Fig 3a; Wald statistic: $\mathrm{df}=1, \mathrm{v}^{2}=71.98, \mathrm{P}<0.0001$ and $\mathrm{df}=1, \mathrm{v}^{2}$ =71.76, $\mathrm{P}<0.0001$, respectively). Alternative food did not significantly affect the number of processed diaspores. Many were recovered elaiosome-less, but a few $(<5 \%)$ offered to A. iberica also presented apparent damage to the embryo. Germination varied according to ant species and was significantly higher in lots offered to P. pallidula. The result of the GLM indicated that the effects of alternative food and its interaction with ant species were marginally significant (Table 4). However, multiple comparisons of least square means indicated that germination success was significantly increased in the presence of alternative food in lots offered to A. iberica (Fig. 3b; Wald statistic: $\mathrm{df}=1, \mathrm{v}^{2}=6.83$, $\mathrm{P}=0.0089$ ). By contrast, germination success was not significantly affected by the availability of alternative food in lots given to P. pallidula and C. cruentatus (Wald

Table 3 Result of the GLM fitting the number of diaspores remaining in the depots to food type (sugar, seed, insect and control) at 12 and $24 \mathrm{~h}$

\begin{tabular}{|c|c|c|c|c|c|c|c|c|}
\hline Fixed effect & \multicolumn{4}{|l|}{$12 \mathrm{~h}$} & \multicolumn{4}{|l|}{$24 \mathrm{~h}$} \\
\hline $\begin{array}{l}\text { Food type } \\
\text { Random effects } \\
\text { Population } \\
\text { Block }\end{array}$ & 3 & 177 & $\begin{array}{l}4.14 \\
Z \\
0.30 \\
2.54\end{array}$ & $\begin{array}{l}0.0073 \\
P \\
03838 \\
0.0056\end{array}$ & 3 & 177 & $\begin{array}{l}3.83 \\
Z \\
0.63 \\
3.14\end{array}$ & $\begin{array}{l}0.0109 \\
P \\
0.2647 \\
0.0008\end{array}$ \\
\hline
\end{tabular}




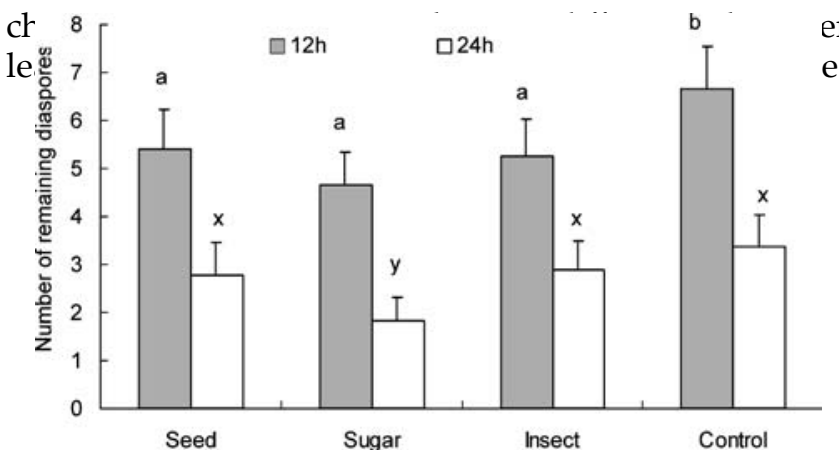

Fig. 2 Number (mean \pm sem) of $\mathrm{H}$. foetidus diaspores remaining after 12 and $24 \mathrm{~h}$ as a function of the associated food. $\mathrm{n}=240$ experimental units. Different letters ( $a-b$ and $x-y)$ denote differences between food treatment at 12 and $24 \mathrm{~h}$, respectively. Multiple comparisons of least-square means were performed with t-test

statistic: $\mathrm{df}=1, \mathrm{v}^{2}=2.49, \mathrm{P}=0.1143$ and $\mathrm{df}=1$, $\mathrm{v}^{2}=2.36, \mathrm{P}=\mathrm{O} .1249$, respectively).

\section{Discussion}

Diaspore-dispersal by ants is a multifactor process that varies in space and time according to modifications in ant communities and diaspore traits (Hughes and Westoby 1990; Mark and Olesen 1996; Gorb and Gorb 1999; Garrido et al. 2002). Several studies have demonstrated that myrmecochore dispersal is often antlimited and varies greatly inside local populations (Smith et al. 1989; Guitian et al. 2003; Ness 2004). Ongoing investigations suggest that in south Spain, populations of $\mathrm{H}$. foetidus seed dispersal is determined more by plant small-scale location than by seed and elaiosome characters (R. Boulay, unpublished results). A possible reason for within-population variations is that dispersal is conditioned by the density of seeds on the ground (Gorb and Gorb 2000). The results of the present study propose an alternative (but non exclusive) explanation and reveal that the outcome of such generalist and asymmetric mutualisms tightly depends on behavioral-mediated indirect effects.

Ants are known to maximize their foraging effort by returning more frequently to rewarding patches and by recruiting nestmates that will defend the food source and cooperate in its retrieval (Cosens and Toussaint 1985;
(Table 2). Carrying species were more frequently observed in sugar food dishes than in insect (Fig. 1a; tmaturate and, over the 2 weeks of ripening, about 20-30 diaspores are generally available for ants at any moment of the day either in the plant or on the ground. Foragers discovering a similar number of diaspores avidly removed them to their nest but rarely recruited nestmates. On the contrary, when highly rewarding sources of sugar or prey were encountered, many foragers were recruited to rapidly initiate group exploitation of the patch. This phenomenon is illustrated in Fig. 2, which shows that sugar and insect dishes were about 4 to 5 times more frequently visited by carrying species than control hellebore dishes.

In general, recruited foragers make large convolutions on their way to the food source to increase the probability of encountering food items (Gordon 1995; Le Breton and Fourcassie 2004). This mechanism explains why even if the alternative food source was never exhausted, some of the recruited foragers easily switched to the hellebore diaspores. Interestingly, among the different treatments, sugar supplementation was the one that most efficiently increased diaspore removal, which could be explained by the overrepresentation of nectarivorous species among the carrying species and by the efficiency of their recruitment. In addition, carbohydrates release more intense searching behavior than other foods as shown in Formica schaufussi (Fourcassie and Traniello 1994) and Lasius niger (Le Breton and Fourcassie 2004) probably because in the wild, sugar sources (mostly nectars and Homoptera honeydew) are more stable than dead insects (Retana et al. 1991; Cerda et al. 1998).

How do these results match with real-world conditions? The study was conducted in an area characterized by small trees (Q. ilex) and shrubs (J. oxycedrus) separated by open gaps. Numerous scavenger and granivorous ants forage on the ground underneath these plants where they find corpses of phytophagous insects and seeds. Nectarivorous species, including C. cruentatus, prefer to climb on to the vegetation to collect Homopteran honeydew. Therefore, $\mathrm{H}$. foetidus shoots that are in intimate contact with these shrubs can indirectly benefit from the visits of ground and canopy foragers with respect to those isolated in open gaps. Our experiment simulated a close association between hellebore diaspores and alternative food, but diaspore dispersal

Table 4 Result of the GLM fitting the number of processed and germinated diaspores per lot as a function of ant colony and species (A. iberica, C. cruentatus and P. pallidula) and food condition (alternative food present versus alternative food absent)

\begin{tabular}{|c|c|c|c|c|}
\hline Dependent variable & Fixed effects & Df & $v^{2}$ & $\mathrm{P}$ \\
\hline \multirow[t]{3}{*}{ Number of processed diaspores } & Ant species & 2 & 8.72 & 0.0128 \\
\hline & Food condition & 1 & 0.06 & 0.8104 \\
\hline & Colony & 15 & 15.71 & 0.4014 \\
\hline \multirow[t]{2}{*}{ Number of germinated diaspores } & Ant species & 2 & 10.28 & 0.0059 \\
\hline & Food condition & 1 & 3.74 & 0.0532 \\
\hline
\end{tabular}



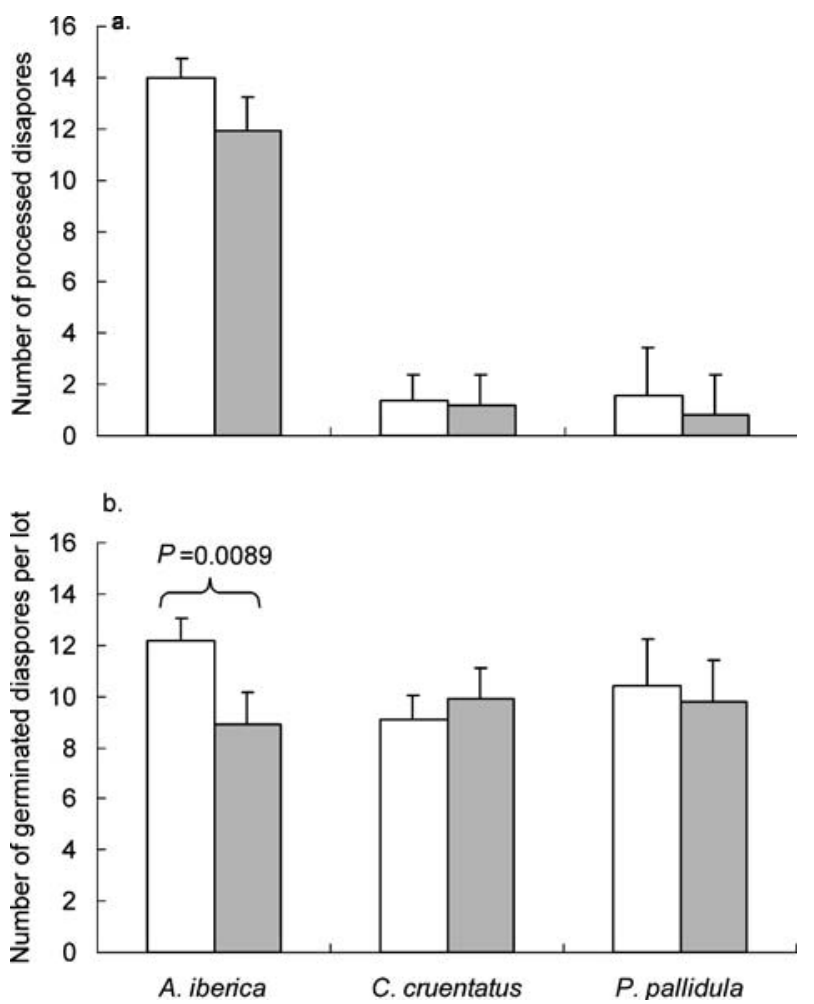

Fig. 3 Number (mean \pm sem) of processed (a) and germinated (b) seeds per lot of 20 diaspores offered to the ant colonies as a function of the availability of alternative food. Open and grey bars denote tests with and without alternative food, respectively ( $n=66$ lots). Multiple comparisons of least-square means were performed using the Wald chi-square statistic

may be favored even if the alternative resource is at a distance of up to $30-40 \mathrm{~cm}$ because, as mentioned earlier, recruited workers generally screen a larger area than just the spot where food was initially discovered. Small colonies of aphids (M. hellebori) that reside at the base of the fruits and that provide sources of sugars to Camponotus species may also contribute to enhanced seed dispersal. Indirect effects of aphids in ant-plant relationships have already been documented, especially when ants offer a protection service (see for example: Messina 1981; Skinner and Whittaker 1981; Ito and Higashi 1991; Floate and Whitham 1994; Gastreich 1999). Though aphids were not the focus of the present study, their effect in our model-system might be limited by unpredictable demographic variations.

An alternative scenario (see Introduction) predicted that the presence of rewarding food could rather diminish diaspore-dispersal due to conflicting interactions between ants. Subordinated ants are known to avoid the use of rewarding patches occupied by a dominant species (Nonacs and Dill 1990, 1991). Numerous intercolonial and interspecific fights were observed around the enriched patches. The carpenter ant, C. cruentatus, most aggressively defended sugar and prey sources against P. pallidula, A. iberica, C. velox, and conspecific colonies. These interactions tended to perturb diaspore removal but the net effect was still beneficial because all the species involved in these fights were carriers. In our focused ant communities non-carrying species attracted by the different food items (e.g., Leptothorax spp, Plagiolepis pygmeae) were not ecologically or behaviorally dominant and they could not keep carrying species from approaching depots. In other Mediterranean habitats, dominated by the invasive Argentine ant Linepithema humile, the association of myrmecochorous diaspores with highly rewarding foods may generate much more conflicting situations with this ineffective disperser, contributing to the reduced dispersal rate observed in infested zones (Christian 2001; Gomez et al. 2003; Carney et al. 2003).

The second experiment demonstrates that once $\mathrm{H}$. foetidus diaspores have been brought to the nest, their fate also indirectly depends on ambient food. Many more diaspores were processed by A. iberica than by C. cruentatus and P. pallidula but, as demonstrated in Fremontodendron decumbens (Boyd 2001), diaspore processing by ants unlikely affects germination rate. Nevertheless, as do many ants that collect elaiosomebearing seeds, A. iberica consumed part of the embryos, which further reduced the probability of germination. Seed predation was amplified when the larvae could not feed on another aliment. Though the observed effect is small, it shows how ambient food can mediate a transition from mutualism to predation. Notwithstanding, the net effect of A. iberica and of granivorous species in general might be beneficial even in absence of alternative food because of the large number of diaspores they normally remove (Retana et al. 2004). Predation was not detected on those seeds retrieved by C. cruentatus and P. pallidula. The former never includes non-myrmecochorous seeds in its diet (Alsina et al. 1988) and the latter might be too small to break hellebore seeds tegument. Indeed, several myrmecochorous plants were shown to have hard coats that confer protection against small granivorous ants such as Pheidole (Rodgerson 1998).

Trait, and especially behavior-mediated indirect effects may be as frequent as density-mediated indirect effects, yet their ecological and evolutionary significance on animal-plant interactions are poorly understood. In a large-scale study carried out in the Iberian Peninsula, Garrido et al. (2002) found a geographic mosaic of wellmatching and mismatching situations between $\mathrm{H}$. foetidus diaspore traits and ant communities. By simulating the association of $\mathrm{H}$. foetidus with different kinds of food, our results shed light on the role played by smallscale plant distribution on diaspore fate. Overall, plants can doubly benefit from alternative resources located in their vicinity through their effect on ant foraging and feeding decisions. Further investigations will however be required to appreciate the long-term consequences of such behavior-mediated indirect effects on the structure of plant communities.

Acknowledgements We thank C. Melian, J. Retana, J. Orivel, M. J. Murray and four anonymous referees for helpful comments on the 
manuscript. Antonio Melia Masia ((Direccion Provincial, Ministerio de Agricultura, Castellon) and Alberto Tinaut (Universidad de Granada) kindly identified aphids and ants respectively. This research was supported by the Spanish "Ministerio de Ciencia y Tecnologia" (projects BOS2000-c03-02 and BOS2003-01536). R.Boulay was funded by the Spanish Ministerio de Educacion, Cultura y Deporte (\# SB2000-0327) and the European Commission (Marie Curie Individual Fellowship\# HPMF-CT-2002-01565), A.J. Manzaneda was funded by McyT predoctoral grant\# FP2000-6031. All experiments comply with Spanish law.

\section{References}

Alsina A, Cerda X, Retana J, Bosch J (1988) Foraging ecology of the aphid-tending ant Camponotus cruentatus (Hymenoptera, Formicidae) in a savanna-like grassland. Misc Zool 12:195-204

Beattie AJ, Hughes L (2002) Ant-plant interactions. In: Herrera C, Pellmyr O (ed) Plant-animal interactions. Blackwell, Oxford, pp 211-235

Beckers R, Deneubourg J-L, Goss S. Pasteels JM (1990) Collective decision making through food recruitment. Insect Soc 37:258267

Berg RY (1975) Myrmecochorous plants in Australia and their dispersal by ants. Aust J Bot 23:475-508

Boyd RS (2001) Ecological benefits of myrmecochory for the endangered chaparral shrub Fremontodendron decumbens (Sterculiaceae). Am J Bot 88:234-241

Brown JS, Mitchell WA (1989) Diet selection on depletable resources. Oikos 54:33-43

Carney SE, Byerley MB, Holway DA (2003) Invasive Argentine ants (Linepithema humile) do not replace native ants as seed dispersers of Dendromcon rigida (Papaveraceae) in California, USA. Oecologia 135:576-582

Cerda X, Retana J, Cros S (1998) Prey size reverses the outcome of interference interactions of scavenger ants. Oikos 82:99-110

Christian C (2001) Consequences of a biological invasion reveal the importance of mutualism for plant communities. Nature 413:635-639

Cosens D, Toussaint N (1985) An experimental study of the foraging strategy of the wood ant Formica aquilonia. Anim Behav 33:541-552

Danell K, Bergstrom R (2002) Mammalian hebivory in terrestrial environments. In: Herrera CM, Pellmyr O (Eds) Plant animal interactions. Blackwell, Oxford, pp 107-131

Detrain C, Deneubourg J-L, Pasteels JM (1999) Decision-making in foraging by social insects. In: Detrain C, Deneubourg J-L, Pasteels JM (eds) Information processing in social insects Bikhauser, Basel, Boston, pp 331-354

Floate KD, Whitham TG (1994) Aphid-Ant interaction reduces Chrysomelid herbivory in a cottonwood hybrid zone. Oecologia 97:215-221

Fourcassie V, Traniello J (1994) Food-searching behavior in the ant Formica schaufussi (Hymenoptera: Formicidae): response of naive foragers to protein and carbohydrate food. Anim Behav 48:69-79

Garrido JL, Rey PJ, Cerda X, Herrera CM (2002) Geographical variation in diaspore traits of an ant-dispersed plant (Helleborus foetidus): are ant community composition and diaspore traits correlated? J Ecol 90:446-455

Gastreich KR (1999) Trait-mediated effects of a theridiid on an ant-plant mutualism. Ecology 80:1066-1070

Gomez C, Pons P, Bas J (2003) Effects of the Argentine ant Linepithema humile on seed dispersal and seedling emergence of Rhamnus alaternus. Ecography 26:532-538

Gorb SN, Gorb EV (1999) Effects of ant species composition on seed removal in deciduous forest in eastern Europe. Oikos 84:110-118
Gorb E, Gorb S (2000) Effects of seed aggregation on the removal rates of elaiosome-bearing Chelidonium majus and Viola odourata seeds carried by Formica polyctena ants. Ecol Res 15:187-192

Gordon D (1995) The expandable network of ant exploration. Anim Behav 50:995-1007

Guitian P, Medrano M, Guitian J (2003) Seed dispersal in Erythronium dens-canis L. (Liliaceae): variation among habitats in myrmecochorous plant. Plant Ecology 169:171-177

Herrera CM, Sanchez-Lafuente AM, Medrano M, Guitian J, Cerda X, Rey P (2001) Geographical variation in autonomous self-pollination levels unrelated to pollinator service in Helleborus foetidus (Ranunculaceae). Am J Bot 88:1025-1032

Holt RD, Kotler BP (1987) Short-term apparent competition. Am Nat 130:412-430

Hughes L, Westoby M (1990) Removal rate of seeds adapted for dispersal by ants. Ecology 71:138-148

Ito F, Higashi S (1991) An indirect mutualism between oaks and wood ants via aphids. J Anim Ecol 60:463-470

Le Breton J, Fourcassie V (2004) Information transfer during recruitment in the ant Lasius niger L. (Hymenoptera:Formicidae). Behav Ecol Sociobiol 55:242-250

Littell R, Milliken G, Stroup W, Wolfinger R (1996) SAS system for mixed models. Cary, North Carolina

Mark S, Olesen JM (1996) Importance of elaiosome size to removal of ant-dispersed seeds. Oecologia 107:95-101

Messina FJ (1981) Plant-protection as a consequence of an antmembracid mutualism-interactions on goldenrod (Solidago $\mathrm{sp}$ ). Ecology 62:1433-1440

Ness JH (2004) Forest edges and fire ants alter the seed shadow of an ant-dispersed plant. Oecologia 138:448-454

Nonacs P, Dill L (1990) Mortality risk vs. food quality trade-offs in a common currency: ant patch preferences. Ecology 71:1886-1892

Nonacs P, Dill L (1991) Mortality risk versus food quality tradeoffs in ants: patch use over time. Ecol Entomol 16:73-80

Nonacs P, Soriano JL (1998) Patch sampling behaviour and future foraging expectations in Argentine ants, Linepithema humile. Anim Behav 55:519-527

Retana J, Cerda X, Espadaler X (1991) Arthropod corpses in a temperate grassland -a limited supply? Holarctic Ecol 14:63-67

Retana J, Pico F, Rodrigo AX, (2004) Dual role of harvesting ants as seed predators and dispersers of a non-myrmechorous Mediterranean perennial herb. Oikos 105:377-385

Rodgerson L (1998) Mechanical defence in seeds adapted for ant dispersal. Ecology 79:1669-1677

Sanchez Yelamo D, Ayerbe L (1984) Algunos aspectos de la ruptura de la dormicion en semillas de Heleboro fetido (Helleborus foetidus L.). Anal INIA ser Agric 27:125-130

SAS Institute (2000) SAS/STAT software: user's guide. SAS Institute Inc., Cary

Sernander R (1906) Entwurf einer Monographie der europaischen Myrmekochoren. Kgl Svensk Vetensk 41:1-409

Skinner G, Whittaker J (1981) An experimental investigation of inter-relationships between the wood-ant (Formica rufa) and some tree-canopy herbivores. J Anim Ecol 50:313 - 326

Smith BH, Forman PD, Boyd AE (1989) Spatial patterns of seeds dispersal and predation of two myrmecochorus forest herbs. Ecology 70:1649-1656

Thomson JD, Chittka L (2001) Pollinator individuality: when does it matter? In: Chittka L, Thompson JD (eds) Cognitive ecology of pollination. Cambridge University Press, Cambridge, pp 191-213

Veech JA (2000) Predator-mediated interactions among the seeds of desert plants. Oecologia 124:402-407

Werner K, Ebel F (1994) Zur Lebensgeschichte der Gattung Helleborus L. (Ranunculaceae). Flora 189:97-130

Werner EE, Peacor SD (2003) A review of trait-mediated indirect interactions in ecological communities. Ecology 84:1083-1100

Wootton JT (1994) The nature and consequences of indirect effects in ecological communities. Annu Rev Ecol Syst 25:443-466 